UDC 575

LBC 28.04

\title{
DEVELOPMENT OF MULTIFUNCTIONAL LABORATORY IN CHIP FOR MOLECULAR DIAGNOSTICS OF INFECTIONS
}

\author{
Natalya G. Sandetskaya \\ Institute of Cellular Therapy and Immunology named after Fraunhofer, Leipzig, Germany \\ Dirk Kulmaher \\ Institute of Cellular Therapy and Immunology named after Fraunhofer, Leipzig, Germany

\section{Christian Cilh} \\ Institute of Cellular Therapy and Immunology named after Fraunhofer, Leipzig, Germany
}

\begin{abstract}
In the present research the authors carry out a comparative analysis of the effectiveness of different methods for isolating bacteria from samples using a MinoLyzer device, a MinoCard chip cartridge and polymerase chain reaction (PCR) method.
\end{abstract}

Key words: DNA, polymerase chain reaction, bacteria, diagnostics.

УДК 575

ББК 28.04

\section{РАЗРАБОТКА МНОГОФУНКЦИОНАЛЬНОЙ ЛАБОРАТОРИИ НА ЧИПЕ ДЛЯ МОЛЕКУЛЯРНОЙ ДИАГНОСТИКИ ИНФЕКЦИЙ}

\author{
Наталья Геннадьевна Сандецкая
}

Институт клеточной терапии и иммунологии им. Фраунгофера, г. Лейпциг, Германия

\section{Дирк Кульмайер}

Институт клеточной терапии и иммунологии им. Фраунгофера, г. Лейпциг, Германия

\section{Кристиан Цильх}

Аннотация. В статье проводится сравнительный анализ эффективности различных способов выделения бактерий из проб с помощью прибора «MinoLyzer», чип-картриджа «MinoCard» и метода полимеразной цепной реакции (ПЦР).

Ключевые слова: ДНК, полимеразная цепная реакция, бактерии, диагностика.

В современной лабораторной диагностике инфекций вместо классических микробиологических методов (выделение патогенного микроорганизма из образца, получение и идентификация его культуры) все чаще используются молекулярно-биологические: выявление специфической ДНК бактерий и вирусов. Такие методы как, например, полимеразная цеп- ная реакция (ПЦР), позволяют обнаружить возбудителя в течение нескольких часов, в то время как микробиологический подход занимает от суток до нескольких недель. Однако для использования молекулярно-биологических методов необходима специально оборудованная лаборатория с несколькими строго разграниченными зонами. Пробоподготовка и 
сами реакции выполняются на нескольких приборах, стоимость которых зачастую не позволяет установить их в небольших лабораториях. Кроме того, техническая сложность методов требует наличия специально обученного персонала, что в отдельных случаях также является ограничивающим фактором. Тем не менее необходимость быстрой диагностики инфекций существует везде, вне зависимости от материальной базы и даже самого наличия лаборатории. Для таких случаев активно разрабатываются лаборатории на чипе: миниатюрные устройства со сложной внутренней структурой, где в микрокамерах для отдельных реакций уже содержатся все необходимые реактивы. Нагревание, смешивание и перемещение образца и реагентов внутри чипа могут осуществляться как автономно, так и с помощью специальных неболыших приборов, куда помещается чип.

В одном из проектов института Фраунгофера в Лейпциге был сконструирован прототип лаборатории на чипе и сопутствующего прибора для обнаружения бактерий в биологических образцах [2]. Прибор под рабочим названием «MinoLyzer» и чип-картридж «MinoCard» позволяют на первом этапе сконцентрировать бактерии из жидкой пробы на поверхности магнитных наночастиц. Затем с помощью магнита бактерии вместе с наночастицами переносятся в следующий реакционный отсек на чипе, где с помощью специального буфера и высокой температуры их клетки будут лизированы для выделения нуклеиновых кислот. Полученная ДНК транспортируется с помощью магнитных микрочастиц другого вида в новую камеру на чипе, где происходит многократная амплификация копий ДНК бактерий путем ПЦР. Этот процесс сопровождается флюоресцентным сигналом, который позволяет отслеживать амплификацию (или ее отсутствие) в реальном времени и дает возможность сделать заключение о наличии определенного патогена в пробе.

Реализация ПЦР в формате лаборатории на чипе на сегодняшний день продемонстрирована многими исследовательскими группами и уже включена в отдельные коммерческие диагностические продукты (например, GeneXpert от компании Cepheid). Однако пробоподготовка для ПЦР на порядок превосхо- дит сложность самой реакции и до сих пор является самым критичным и трудоемким этапом как в обычной лаборатории, так и в интегрированном формате на чипе [4]. В данном проекте выделение бактерий и их ДНК было приоритетным направлением исследования. В первую очередь была исследована эффективность различных способов выделения бактерий из пробы. Для этого, в частности, применялись антитела или антибактериальные пептиды, иммобилизованные на поверхности магнитных частиц. Эти молекулы распознают элементы клеточной поверхности бактерий и связываются с ними, удерживая клетки возбудителя. Используя магнит, можно получить обогащенную фракцию бактерий на магнитных частицах в объеме всего нескольких микролитров, в то время как исходный объем пробы может составлять несколько миллилитров. Этот этап пре-обогащения крайне важен для миниатюризированных устройств, так как исходные объемы клинических образцов почти всегда слишком велики для лаборатории на чипе.

Для выделения бактерий были опробованы различные типы магнитных частиц. Так, наночастицы по сравнению с микрочастицами обладают значительно большей поверхностью для связывания бактерий, однако негативным эффектом этого является повышенное неспецифическое связывание прочих компонентов пробы (например, белков крови). На следующих этапах это может приводить к снижению эффективности ПЦР [1]. Для предотвращения этого был разработан интегрированный метод очистки ДНК на чипе с помощью других магнитных частиц, которые удерживают ДНК на своей поверхности при определенном рН среды (около 5) и освобождают связанные молекулы при более высоком рН (около 8). При этом белки и прочие компоненты пробы - потенциальные ингибиторы ПЦР - остаются незатронутыми, в то время как ДНК перемещается с помощью магнита в камеру для амплификации. Контролируемое изменение уровня кислотности в разных реакционных отсеках чипа удалось реализовать путем подбора состава и концентрации буферных растворов в разных сегментах MinoCard.

Прибор MinoLab осуществляет функции транспортировки магнитных частиц, поддер- 
живает необходимый температурный режим отдельных реакций и включает модуль для детекции флюоресцентного сигнала. Все функции прибора могут быть запрограммированы в различных режимах и комбинациях. Для демонстрации многофункциональности этой платформы был реализован другой тип реакции амплификации ДНК, LAMP (Loop-mediated isothermal amplification), отличный от ПЦР по молекулярным и температурным характеристикам. В то время как ПЦР требует сложного циклического изменения температуры на протяжении 1-2 часов, изотермальная амплификация LAMP протекает при постоянной температуре $65{ }^{\circ} \mathrm{C}$ и занимает в $2-3$ раза меньше времени, при этом не уступая ПЦР в чувствительности [3].

Описанная лаборатория на чипе в настоящий момент находится на стадии действующего лабораторного прототипа, ее аналитические характеристики, в частности, чувствительность, требуют оптимизации для соответствия клиническим концентрациям микроорганизмов в био- логических жидкостях. В связи с этим авторы не приводят количественных данных, но демонстрируют результаты отдельных экспериментов по анализу искусственных образцов.

\section{СПИСОК ЛИТЕРАТУРЫ}

1. Al-Soud, W. A. Purification and Characterization of PCR-Inhibitory Components in Blood Cells / W. A. Al-Soud, P. Rådström // Journal of Clinical Microbiology. - 2001. - Vol. 39 (2). -P. 485-493.

2. An integrated versatile lab-on-a-chip platform for the isolation and nucleic acid-based detection of pathogens / N. Sandetskaya [et al.] // Future Science OA. - 2017. - Vol. 3 (2).

3. Loop-mediated isothermal amplification of DNA/ T. Notomi [et al.] // Nucleic Acids Research. 2000. - Vol. 28 (12).

4. Rahman, M. M. Nucleic acid sample preparation for in vitro molecular diagnosis: from conventional techniques to biotechnology / M. M. Rahman, A. Elaissari // Drug Discovery Today. - 2012. - Vol. 17 (21-22). - P. 1199-1207.

\section{Information about the Authors}

Natalya G. Sandetskaya, Researcher of Department of Diagnostics, Laboratory for Nanotechnology, Institute of Cellular Therapy and Immunology named after Fraunhofer, Fraunhofer IZI, Perlickstrasse, 1, 04103 Leipzig, Germany, sandenat@mail.ru.

Dirk Kulmaher, Researcher of Department of Diagnostics, Laboratory for Nanotechnology, Institute of Cellular Therapy and Immunology named after Fraunhofer, Fraunhofer IZI, Perlickstrasse, 1, 04103 Leipzig, Germany, sandenat@mail.ru.

Christian Cilh, Researcher of Department of Diagnostics, Laboratory for Nanotechnology, Institute of Cellular Therapy and Immunology named after Fraunhofer, Fraunhofer IZI, Perlickstrasse, 1, 04103 Leipzig, Germany, sandenat@mail.ru.

\section{Информация об авторах}

Наталья Геннадьевна Сандецкая, научный сотрудник отдела диагностики, лаборатории нанотехнологии, институт клеточной терапии и иммунологии им. Фраунгофера, Fraunhofer IZI, Perlickstrasse, 1, 04103 Leipzig, Germany, sandenat@mail.ru.

Дирк Кульмайер, научный сотрудник отдела диагностики, лаборатории нанотехнологии, институт клеточной терапии и иммунологии им. Фраунгофера / Fraunhofer IZI, Perlickstrasse 1, 04103 Leipzig, Germany, sandenat@mail.ru.

Кристиан Цильх, научный сотрудник отдела диагностики, лаборатории нанотехнологии, Институт клеточной терапии и иммунологии им. Фраунгофера / Fraunhofer IZI, Perlickstrasse 1, 04103 Leipzig, Germany, sandenat@mail.ru. 